\title{
A CONSTITUIÇÃo DA VEIA PORTA EM BOVINOS DA RAÇA NEIORE
}

\author{
THE CONSTITUTION OF THE PORTAL. VEIN IN BOVINES OF NELORE BREED
}

Nilton Abreu ZANCO'; Ana Luisa RE(;INA TO²; Maria Angélica MIGLINO’; Iiberato João Afonso IIDIO ${ }^{4}$

\begin{abstract}
RESUMO
Estudou-se a constituição da veia porta em bovinos da raça Nelore. Utilizaram nesse trabalho 30 fetos de bovinos, os quais tiveram seus sistemas da veia porta (extra-hepático) injetados com látex Neoprene 650 corado e dissecados. Os resultados do trabalho mostram variações no arranjo das raízes da veia porta e dos afluentes que compōem estes troncos. A disposição mais frequente é a veia porta formada pelas veias esplênica, gastroduodenal e mesentérica cranial.
\end{abstract}

UNITERMOS: Veia porta: Bovinos: Nelore

\section{INTRODUÇĀO E I.ITERATURA}

Interessados no estudo anatômico da constituição do tronco da veia porta $\mathrm{cm}$ bovinos da raça Nelore, resolvemos verificar a confluência das raízes desse vaso em uma série suficiente de animais para validade estatística dos achados.

A busca bibliográfica demonstrou que os seguintes autores trataram do assunto em ruminantes: LESBRE' (1922); BRUNI; ZIMMERL' (1951); KUHN; ROTHKEGEL' (1962); HOROWITZ; VENZKE ${ }^{5}$ (1966); GETTY $^{3}$ (1981); GHOSKAL et al. ${ }^{4}$ (1981); NICKEL et al. ${ }^{8}(1981)$ e DYCE et al. $^{2}$ (1987).

\section{MATERIAL E MÉTODO}

Na realização deste trabalho utilizamos 30 fetos de bovinos da raça Nelore, retirados de mães oriundas de diversas criações do Estado de São Paulo.

Injetamos a veia porta de cada feto com látex do tipo Neoprene 650 corado e fixamos as peças, já convenientemente reduzidas, em solução aquosa de formol a $10 \%$. A seguir dissecamos as raízes da veia porta, procedemos de modo a fazer de cada peça um esquema e fotografamos as peças mais interessantes para ilustração do trabalho.

\section{RESULTADOS}

Encontramos a veia porta formada pela união de tributários que drenam os estômagos (rúmen, retículo, omaso e abomaso), duodeno, jejuno, íleo, ceco, cólons (sigmóide, espiral e terminal), reto, fígado, pâncreas e baço. Das 30 peças estudadas verificamos que: em 28 preparações, ou seja, 93,3\% (14 machos e 14 fêmeas) a veia porta se mostrava formada por três raízes: veia esplênica, veia gastroduodenal e veia mesentérica cranial. Nos dois casos restantes, ou seja, 6,7\% ( 1 macho e 1 fêmea) a veia porta era constituída pela união de 4 afluentes: veia esplênica, veia gástrica dircita, veia gastroomental direita e veia mesentérica cranial.

Analisando separadamente a disposiçāo de cada raiz verificamos que: a veia esplênica, a mais calibrosa da veia porta, se dispõc em ângulo reto proveniente do baço. Em seu trajeto recebe tributárias que drenam a maior parte dos estômagos (rúmen, retículo e omaso), parte do pâncreas, baço e omento. Em todos os casos estudados a veia esplênica é formada primeiramente por um tronco que drena as porções gástricas (rúmen, retículo e omaso). Existem entretanto variações na sua formação, a saber: em 28 casos, ou seja, $93,3 \%$ (13 machos e 15 fêmeas) o tronco acima citado é formado pela confluência de 2 raízes. Uma delas é responsável pela drenagem do saco ventral esquerdo do rúmen (veia ruminal esquerda) e do retículo (veia reticular) e a outrá raiz drena o omaso, na sua superfície externa justaposta do rúmen (veia gastroomental esquerda) e caminha pela face oposta do órgão (veia gástrica csquerda). Nas 2 peças restantes, ou seja, 6,7\% (2 machos) a formação do tronco resulta da confluência de 3 raízes, inexistindo a presença do tronco formado pelas veias que drenam o saco ventral esquerdo do rúmen e retículo.

Em todos os fetos dissecados, o segundo afluente que chega à veia esplênica é responsável pela drenagem do saco ventral direito do rúmen (veia ruminal direita). Verificamos em todos

\footnotetext{
- Médico Veterinário - Faculdade de Medicina Veterinária "Octúvio Bastos", São João da Boa Vista, SP. Brasil

2- Médico Veterinário - Faculdade de Medicina Veterinária "Octávio Bastos". São Jeáo da Boa Vista, SP, Brasil

3. Professor Associado, Faculdade de Medicina Veterinánia e Zamtecnia da USP

1 - Professor Visitante" - Escola Paulista de Medicina, São Paulo, SP. Brasil e Professor Emérito do Medical College of Ohio, USA
} 
ZAN( (). N. A.: RF(iINATO), A. I..: MIGI.INO), M. A.: DIDIO), L. J. A. A constituição da veia porta em bovinos da raça Nelore. Braz. J. vet. Res. anim. Sci., Säo Paulo. v. 31, 11.1, p. 1.3-8, 1904.

os casos duas raizes responsáveis pela drenagem do parênquima do baço, contribuindo para a formação da veia esplênica. lim afluente, proveniente do baço, penetrava no pâncreas $e$ posteriormente atingia a veia esplênica. A presença de um pequeno afluente da veia esplênica drenando o omento (radícula omental), foi também. constante. Dois vasos são responsáveis pela drenagem venosa do omaso. (O primeiro deles, que se dispõe na superfície externa do órgão justaposta ao rúmen (veia gastroomental esquerda), anastomosa-se sempre com a veia que drena a grande curvalura do abomaso (veia gastroomental direita). A segunda raiz, disposta na superfícic do órgão justaposta ao duodeno (veia gástrica esquerda), anastomosa-se com a veia que drena a pequena curvalura do abomaso (veia gástrica direita).

A veia gastroduodenal é a raiz menos calibrosa que contribui para a formação da veia porta. Surge próximo ao pâncreas e é responsável pela drenagem do pâncreas, duodeno e abomaso.

A presença da veia gastroduodenal ocorre em 28 casos, ou seja, 93,3\% (14 machos e 14 fêmeas). Em 27 casos, ou seja, $90 \%$ (14 machos e 13 fêmeas) sua formação se dava pela união de três raízes: uma raiz que drenava o pâncreas c o duodeno (veia pancreaticoduodenal cranial), uma raiz que drenava a curvatura maior do abomaso (veia gastroomental direita), e uma terceira raiz que drenava a curvatura menor do abomaso (veia gástrica direita). Em I dos casos, ou seja. 3,3\% (1 fêmea) a veia gastroduodenal cra formada por duas raízes que drenavam a curvatura maior (veia gastroomental direita) c a curvatura menor do abomaso (veia gástrica direita). Neste caso observamos que a veia responsável pela drenagem e parte do pâncreas e duodeno (veia pancreaticoduodenal cranial) era tributíria da veia gastroomental direita. Em 2 fetos, ou seja, 6,7\% (1 macho e I fêmea), verificamos a ausência da veia gastroduodenal, sendo que nestas oportunidades as veias gastroomental e gástrica dircita constituíam atluentes que chegavam diretamente à veia porta. A veia que drenava a curvatura maior do abomaso (veia gastroomental direita) recebia a veia que drenava parte do pâncreas e do duodeno (veia pancreaticoduodenal cranial). Em todas as preparaçōes observamos anastomoses entre as veias que drenavam as curvaturas maior e menor do abomaso com ayueles alluentes responsáveis pela superfície externa do omaso (parte justaposta ao rúmen e ao duodeno). Havia, também, anastomoses entre as veias que drenavam parte do pâncreas e duodeno, tributárias da veia gastroduodenal ou da veia gastroomental direita (veia pancreaticoduodenal cranial) com as veias tributárias da veia mesentérica cranial que drenavam parte do pâncreas, do duodeno e do jejuno (veia pancreaticoduodenal caudal).

A veia mesentérica cranial é um conspicuo afluente da veia porta que drena parte do pâncreas e o trato intestinal, duodeno, jejuno. íleo, ceco, cólon e reto. Em 25 casos, ou seja, 83.3\%
(13 machos e 12 fêmeas), um tronco drenava partes do intestino delgado e do intestino grosso (íleo, ceco e cólon) e parte do pâncreas (veia pancreaticoduodenal caudal). Nestes casos o referido tronco era formado por veias jejunais, a do cólon terminal (veia cólica esquerda), a do cólon ascendente íleo e ceco (veia ileocecocólica), a do cólon espiral, drenado por afluentes cólicos a a do cólon descendente e sigmóide (veia cólica direita). Em I caso, ou seja, 3,33\% (macho) o citado tronco cra constituído por duas raízes venosas, uma delas proveniente do cólon terminal (veia cólica esquerda) e do íleo, cólon e ceco (veia ileocecocólica), e a outra formada por raízes provenientes do cólon espiral (ramos cólicos) e do cölon descendente c sigmóide (veiáa cólica direita). Em 4 casos, ou seja, 13,3\% (1 macho e 3 fêmeas) a veia que drenava o cólon terminal atec a porção média do reto atluía para a veia mesentérica cranial.

Observamos anastomose de uma raiz tributária da veia mesentérica cranial, que drenava parte do pâncreas e do duodeno (pancreaticoduodenal caudal), com a raiz tributária da veia gastroduodenal ou da gastroomental direita, que lambém drenava parte do pâncreas c do duodeno (pancreaticoduodenal cranial).

Na totalidade dos preparados, verificamos anastomoses entre tributárias da mesentérica cranial. A que drenava a porção fínal do cólon e se dirigia em direção ao ânus (veia mesentérica caudal) anastomosava-se com a veia que drenava o cólon terminal e seguia até a porção média do reto (veia cólica esquerda).

Ocorreram em todos os casos anastomoses entre a veia que drenava o cólon terminal (veia cólica esquerda) e a veia que drenava parte do cólon terminal e início do cólon descendente (veia cólica média). Esta por sua vez anastomosou-se em 26 casos, ou seja, 86,7\% ( 13 machos c 13 fêmeas) com o tronco formado pelas veias que drenam o íleo, o cólon e o ceco (veia ileocecocólica). Em 4 casos, ou seja, 13,3\% (2 machos e 2 fêmeas) a anastomose se dava com a veia mesentérica cranial. Um segundo ramo da veia cólica média anastomosou-se ẹm todos os casos com a veia que drenava o cólon descendente e sigmóide (veia cólica direita).

Pudemos observar sempre a ocorrência de anastomoses entre as veias que drenavam o cólon descendente e sigmóide (veia cólica direita) com as veias que drenavam o cólon espiral (raizes cólicas). Constatamos também anastomoses entre as veias que drenavam a porção fïnal do jejuno (veias jejunais) com as veias que drenavam o íleo (veia ileal) e o ceco (veia cecal). As veias jejunais anastomosavam-se entre si. Em todas as oportunidades a veia que drenava o íleo (veia ileal) anástomosava-se, na porção inicial do ceco, com as veias que drenavam o cólon e o ceco (veia colicocecal). 
7.ANCO, N. A.; REGINATO, A. L.; MIGLINO, M. A.; DIDIO, L. J. A. A constituição da veia porta em bovinos da raça Nelore. Braz. J. vet. Res. anim. Sci., Sāo Paulo, v. 31, n.I, p. 13-8, I994.

\section{COMENTÁRIOS}

A disposição das raízes formadoras da veia porta nos ruminantes tem sido descrita diferentemente pelos diversos autores que estudaram este assunto nos ruminantes. $O$ tronco formado por duas veias mesentéricas, uma esplênica e uma veia gástrica "anterior", constitui segundo LESBRE7 (1922) a veia porta. Esta de acordo com BRUN1; ZIMMERL' (1951) é formada a partir da confluência da veia mesentérica cranial e da veia esplênica, recebendo constantemente a veia gastroduodenal e ocasionalmente um vaso pancreático. Para GETTY $^{3}(1981)$ a veia gastroduodenal, raízes pancreáticas, a veia esplênica, a veia pancreaticoduodenal caudal e as veias mesentéricas cranial e caudal são afluentes terminais da veia porta.

Na maioria das nossas preparaçōes encontramos resultados semelhantes aos de NICKEL et al. ${ }^{8}(1981)$ e DYCE et al. ${ }^{2}$ (1987) quando notamos que a veia porta é um vaso formado pela união de tributárias que drenam os estômagos (rúmen, retículo, omaso e abomaso), duodeno, jejuno, íleo, ceco, cólon (sigmóide, espiral e terminal), reto, fígado, pâncreas e baço. Ela é formada por três raízes: a veia esplênica, a veia gastroduodenal e a veia mesentérica cranial. Somente em dois casos pertencentes a um macho e uma fêmea de bovinos da raça Nelore encontramos uma disposição não mencionada pelos autores consultados, oportunidade em que verificamos a veia porta resultante da confluência de quatro afluentes: veia esplênica, veia gástrica direita, veia gastroomental direita e veia mesentérica cranial.

Analisando, agora, separadamente cada raiz que entra na formação do tronco da veia porta, começaremos com a veia esplênica - LESBRE ${ }^{7}$ (1922) - a qual segundo o autor tem sua origem a partir da anastomose das veias gastroomentais direita e esquerda e que recebe afluentes gástricos, esplênicos e omentais e que se une à veia mesentérica caudal e veia gástrica posterior. Outros tratadistas não concordam com este arranjo.

Parece haver opinião concordante (BRUNI; ZIMMERL', 1951; KUHN; ROTHKEGEL', 1962 e HOROWITZ; VENSKE $^{5}, 1966$ ) em considerá-la parte de um tronco denominado gastroesplênico, afluente mais calibroso (BRUNI; ZIMMERL', 1951) ou raiz menos calibrosa (KUHN; ROTHKEGEL', 1962, em ovinos) da veia porta e que de acordo com HOROWITZ; VENZKE ${ }^{5}$ (1966) é essencialmente homólogo à veia esplênica do homem.

$\mathrm{Na}$ formação deste tronco entram as raízes denominadas veia ruminal direita, veia esplênica, as quais formam um tronco comum que recebe outro tronco comum constituído pela veia ruminal esquerda, veia do retículo, veia gástrica esquerda e veia reticular (BRUNI; ZIMMERL', 1951). A primeira raiz formada pela veia lienal e veia ruminal direita recebe, de acordo com KUHN; ROTHKEGEL' (1962), três a cinco afluentes pancreáticos e drena os segmentos craniais e esquerdos do rúmen após ter emergido do hilo do baço.

Considerando particularmente os caprinos, HOROWITZ; VENZKE $^{s}$ (1966) afirmam que a veia esplênica recebe constantemente a veia gástrica esquerda, um vaso que no homem é pequeno e que caminha independente da veia porta. A veia esplênica, segundo eles, recebe regularmentc a veia ruminal direita e não muito freqüentemente a veia reticular.

No parecer de GOSKAL et al. ${ }^{+}$(1981) a veia esplênica recebe em disposição trifurcada as veias reticular, ruminal esquerda e gástrica esquerda, recebendo ainda durante o seu trajeto a veia ruminal direita. O citado vaso drena o sangue não só do baço, como também do rúmen (veias ruminais direita e esquerda), retículo (veia reticular), omaso e abomaso (veia gástrica esquerda), além do pâncreas (GETTY³ ${ }^{3}$ 1981).

Ao considerar nos bovinos da raça Nelore a vcia esplênica, raiz mais calibrosa da veia porta, e ao verificar seu território de drenagem (rúmen, retículo, omaso, parte do pâncreas, baço e epiplon), bem como ao encontrar em $93,3 \%$ das nossas dissecações sua origem constituída por dois troncos de formato bifurcado, sendo um deles formado pela veia ruminal esquerda e veia reticular, e o outro formado pela veia gastroomental esquerda e veia gástrica esquerda, concluímos que nossos achados confirmam as referências de DYCE et al. ${ }^{2}$ (1987).

É bem verdade que os preparados referentes a dois animais da raça Nelore mostraram relativamente a formação do tronco esplênico, disposição trifurcada, inexistindo a presença de um tronco formado pelas veias que drenam o saco ventral esquerdo do rúmen e retículo, porém, o segundo afluente da veia lienal era constantemente a veia ruminal direita.

Constante também foi, nas nossas preparações, a presença de duas raízes responsáveis pela drenagem do baço; uma delas recebia afluentes pancreáticos e omentais, à semelhança das indicações apontadas por NICKEL et al. ${ }^{8}$ (1981).

De outra parte, verificamos sempre a presença de anastomoses entre as veias responsáveis pela drenagem do omaso e do abomaso (veias gastroomentais direita e esquerda e veias gástricas direita e esquerda) à semelhança dos achados de KUHN; ROTHKEGEL ${ }^{6}$ (1962); GETTY $^{3}$ (1981) e de GHOSKAL et al. ${ }^{4}$ (1981).

Quanto aos autores que consideraram o tronco gastroesplênico como afluente da veia porta, deve-se levar em conta a opinião de KUHN; ROTHKEGEL ${ }^{6}$ (1962) que, estudando o assunto 
ZANCO, N. A.; RI:GI.NATO, A. I..; MIGL.jNO. M. A.: DIDIO, L. J. A. A constituiçāo da veia porta em bovinoss da raça Nelore. Braz. J. vet. Res. anim. Sci. São Paulo, v. 31. I. 1, p. 13-8, 1994.

em ovinos, encontraram disposição diferenciada de arranjos venosos do que ocorre no grandes ruminantes ou seja: a segunda raiz da veia gastroesplênica é formada pela veia ruminoreticular que corresponde à veia reticular dos grandes ruminantes associada à veia ruminal direita inexistente no carneiro. A veia ruminal esquerda é formada pela veia gastroomental esquerda e pela veia reticular. Foram verificadas ainda anastomoses entre os afluentes da veia ruminoreticular com aqueles das veias ruminal esquerda e reticular.

Nos caprinos HOROWIT'Z; VENZKE ${ }^{5}$ (1966) encontram sempre a veia ruminal esquerda e a veia reticular comportando-se como alluentes da veia gástrica esquerda. Esta, a seu lurno, se origina a partir de quatro afluentes tributários dos ramos arteriais. A veia ruminal esquerda é o seu último afluente próximo à sua desembocadura na veia esplênica.

Também de acordo com GHOSKAL et al. ${ }^{4}(1981)$ a veia ruminal esquerda é constante tributária da veia gástrica esquerda e menos frequientemente da veia reticular esquerda. Os afluentes omentais são tributários da veia ruminal direita nos caprinos (HOROWITZ; VENZKE's 1966).

Analisando agora a veia gastroduodenal, verificamos que muitos dos autores estudiosos do assunto relativo à constituição da veia porta não mencionam este vaso tendo em vista as opiniōes diferentes atinentes à individualidade desta raiz.

Nos ovinos, KUHN; ROTHKEGEL' (1962) afirmam que a veia gastroduodenal é formada por três afluentes: a veia gástrica direita, a veia gastroomental direita e a veia pancreaticoduodenal cranial. Estas últimas formam um tronco que se une à veia gástrica direita, cujas raízes se anastomosam em rede com a veia gástrica esquerda. A veia pancreaticoduodenal cranial é a raiz menos calibrosa da veia gastroduodenal e se anastomosa com a veia pancreaticoduodenal caudal.

Esta afirmação não concorda com a de HOROWITZ; VEN/KE:5 ( 1966 ) quando referem que a veia gastroduodenal é formada pelas veias pancreaticoduodenal e gastroomental direita. Excepcionalmente a veia gastroduodenal recebe a veia gástrica dircita como uma tributária imediata nos caprinos. Em um caso, os autores encontraram a veia gastroomental direita, e a veia pancreaticoduodenal formava um tronco contínuo que se ligava a tributário pancreaticoomental da veia mesentérica cranial. Em outros dois animais a veia pancreaticoduodenal cranial se unia $\mathrm{com}$ a veia pancreaticoduodenal tributária da veia mesentérica cranial.

Na opinião de GHOSKALet al. ${ }^{+}(1981)$, à veia gastroduodenal usualmente recebia a veia pancreaticoduodenal cranial que se anastomosava com a veia pancreaticoduodenal caudal.
Quando estes autores se referem à veia gástrica direita, vaso disposto na curvatura menor do abomaso, mencionam que algumas raízes duodenais e gástricas são afluentes deste vaso.

A anastomose entre os dois afluentes pancreaticoduodenais é referida também por NICKEL el al. ${ }^{\circ}$ (1981), os quais reconhecem a veia gastroduodenal formada pela reunião da veia gástrica direita, gastroomental direita e pancreaticoduodenal cranial, opinião já evidenciada por KUHN; ROTHKEGEL' (1962) e semelhante aos resultados que por ora descrevemos para a maioria $(90 \%$ ) dos animais utilizados na nossa pesquisa.

Entretanto, a presença da veia gastroduodenal não foi uma constante nos resultados da nossá pesquisa; ela apareceu em $28(93,3 \%)$ dos casos estudados. Nas 2 oportunidades onde se verificou at sua ausência, as veias gastroomental e gástrica direita constituíam afluentes que chegavam diretamente à veia porta. fato nunca antes assinalado. Por outro lado, a veia que drenava a curvatura maior do abomaso (gastroomental direita) recebia a veia pancreaticoduodenal cranial à semelhança dos arranjos encontrados para os ovinos (KUHN: ROTHKEGEL', 1962) e caprinos (HOROWITZ: VENZKEs. 1966).

Finalmente, a veia mesentérica cranial, uma combinação das veias intestinais, segunda tributária da veia porta (GHOSKAI. et al. ${ }^{4}, 1981$; DYCE et al..$^{2}$ 1987) e no parecer de LESBRE ${ }^{7}$ (1922) constituída pelas veias do intestino delgado, pela veia ileocecal, pelas duas veias cecais, pela veia cólica primitiva e por uma veia que procede originalmente do cólon flutuante. Um tronco ileocecocólico e um tronco intestinal se juntam (BRUNI; ZIMMERL', 195I; KUHN, RO'THKEGEL', 1962) para formar a veia mesentérica cranial, que ainda recebe tributários pancreáticos e una veia pancreaticoduodenal caudal (KUHN: ROTIKEGEL", 1962). Aliás, a raiz pancreáticoduodenal caudal (GHOSKAL el al. ${ }^{4}$. 1981; NICKEL, et al. ${ }^{\circ}, 1981$ ) é um dos afluentes da veia mesentérica cranial. Entretanto, os arranjos formados na constituição da veia mesentérica cranial são os mais diversos, tanto que de acordo com GHOSK AL et al. ${ }^{4}$ (1981), os primeiros afluentes do citado vaso são o afluente pancreaticoduodenal caudal e veia cólica média. Posteriormente a veia mesentérica cranial recebe um tronco que em disposição trilurcada formado pelas veias ileocólica, cólica direita e ileal, drena o cólon espiral. o cólon ascendente e o ceco.

Para NICKEL et al. ${ }^{8}(1981)$, a veia mesentérica cranial é formada pela confluência das veias procedentes do jejunoíleo (veias jejunais e veia pancreaticoduodenal caudal), cólon e ceco (veia ileocólica).

A veia mesentérica caudal, considerada por $\operatorname{GETTY}^{3}(1981)$; 
NICKEL et al. ${ }^{8}(1981)$, raiz da veia porta, recebe a veia cólica média (oriunda do cólon transverso e alça distal do cólon), a veia cólica (que é a continuação da veia cólica média no cólon descendente) e a veia retal cranial.

Para LESBRE? (1922), a veia mesentérica caudal inicia-se sob o reto por grossas raízes hemorroidárias, dirige-se para frente entre as duas lâminas mesentérica e cólica, para mais tarde se unir à veia esplênica, e em seguida à veia mesentérica cranial para formar a veia porta.

Particularmente as veias cólicas consideradas por alguns como parte do tronco ileocecocólico (BRUNI; ZIMMERL', 1951) ou ileocólico (LESBRE?, 1922; GHOSKAL et al. ${ }^{4}$ 1981; NICKEL et al. ${ }^{\circ}, 1981$ ) têm disposição variada, ou seja a veia cólica média (GHQSKAL et al. ${ }^{4}, 1981$ ) anastomosa-se com a veia cólica direita e a cólica esquerda continua-se com a veia retal cranial que se anastomosa com a veia retal caudal. A veia cecal e dois afluentes ileais anastomosavam-se com a veia ileal. A cólica direita supre a parte espiralada do cólon especialmente a parte centrífuga e anastomosa-se com as veias ileocólica e cólica média. A veia ileal representa a raiz. final da veia mesentérica cranial após ter recebido o tronco das jejunais. As veias jejunais anastomosam-se entre si.

Nos bovinos da raça Nelore, observamos que a veia mesentérica cranial é um robusto afluente da veia porta que drena parte do pâncreas e quase todo tracto intestinal (íleo, ceco, cólon e reto).

A semelhança dos resultados de GHOSKAL et al. ${ }^{4}$ (1981) e NICKEL et al. ${ }^{8}$ ( 1981 ) a veia pancreaticoduodenal caudal era sempre um afluente da veia mesentérica cranial, porém, a veia mesentérica caudal contrariamente ao observado por LESBRE? (1922); GETTY” (1981) e NICKELet al. ${ }^{8}$ (1981) era afluente da veia mesentérica cranial, que por ordem recebia as jejunais e as tributárias responsáveis pela drenagem do íleo, cólon e ceco.

Em 83,3\% dos 30 casos estudados observa-se um tronco comum com quatro raízes ou seja, veia cólica esquerda, veia ileocecocólica, raízes cólicas (responsáveis pela drenagem do cólon espiral) e veia cólica direita (que drenava o cólon descendente e sigmóide). Este tronco apresentava três raizes em 13,3\% das peças ou seja, uma veia ileocecocólica, afluentes cólicos (procedentes do cólon espiral) e veia cólica direita ou ainda duas raizes $(3,3 \%)$ venosas, uma delas formada pela veia cólica esquerda e veia ileocecocólica e a outra pelos afluentes cólicos (cólon espiral) e veia cólica direita.

Verificamos ainda em nossos resultados que a veia responsávẹl pela drenagem do cólon terminal chegava independente na veia mesentérica cranial $(1,3,3 \%)$.
As anastomoses entre as raízes formadoras da veia mesentérica cranial são amplas como já confïrmado por outros autores tais comoGHOSKALet al. ${ }^{4}(1981)$, c ocorrem entre as pancreaticoduodenais cranial e caudal, entre a veia mesentérica e a veia cólica esquerda e a veia cólica média e entre esta com a veia ileocecocólica $(86,6 \%)$, ou mesmo com a veia mesentérica cranial $(13,3 \%)$.

Foram vistas também anastomoses das raízes da veia cólica média com a veia cólica direila $(13,3 \%)$ e desta com os afluentes cólicos (oriundos do cólon espiral). As veias jejunais se comunicavam com a veia ileal e com a veia cecal e entre si. A veia ileal anastomosava-se também em todas as ocasiões com a veia colicocecal.

\section{CONCLUSÕES}

1. A veia porta de bovinos Nelore é muito mais freqüente triradicular $(93,3 \%$ dos casos) do que quadri-radicular $(6.7 \%)$.

2. As 3 raízes do tronco da veia porta são as veias esplênica gastroduodenal e mesentérica cranial. Nos casos de 4 raízes as veias que constituem o tronco portal são a esplênica, a mesentérica cranial, a gástrica dircita e a gastroomental direita.

3. A veia esplênica reccbe tributárias que drenam a maior parte dos estômagos, ou seja, rúmen, retículo e omaso $(100 \%)$, parte do pâncreas, o baço c o omento. O tronco da esplênica ć formado por 2 raízes em $93,3 \%$ dos casos, uma que drena o saco ventral esquerdo do rúmen (veia ruminal esquerda) e do retículo (veia reticular) e outra que drena a superfície externa do omaso justaposta ao rúmen (veia gastroomental esquerda) enquanto a face oposta do órgāo é drenada pela vcia gástrica esquerda.

4. Em todos os fetos a veia esplênica aflui à veia ruminal direita, responsável pela drenagem do saco ventral direito do rúmen.

5. Duas veias são responsáveis pela drenagem do parênquima do baço, uma das quais penetra no pâncreas e, a seguir, aflui à vcia esplênica. Uma constante radícula omental é tributária da veia esplênicá.

6. O omaso é drenado pelas veias gastroomental esquerda (que se anastomosa com a homônima da direita) e gástrica esquerda (que se anastomosa com a direita).

7. A veia gastroduodenal ocorre em $93,3 \%$ dos casos e em $90 \%$ possui três raízes: veias pancreaticoduodenal cranial, gastroomental direita e gástrica direita. 
ZANC O. N. A.: REGINATO, A. I..: MIGI.INO. M. A.: DIDIO. L. J. A. A constituiçăo da veia porta em bovinos da raça Nelore. Braz. J. vet. Res. anim. Sci. Såo Pasulo, v. 31, n.1. p. 13-8, 1994

8. A veia mesentérica cranial em $83,3 \%$ dos casos drena parte do pâncreas (veia pancreaticoduodenal caudal) $\mathrm{e}$ quase todo o trato intestinal (veias jejunais, cólicas direita e esquerda, ileocecocólica, cólicas do cólon espiral, descendente e sigmóide, e retal).
9. Em todos os casos existem anastomoses entre as tributárias da veia mesentérica cranial, inclusive a que drena a parte final do cólon (veia mesentérica caudal) com a proveniente da porção média do reto (veia cólica esquerda). A veia cólica média se anastomosa em $86,7 \%$ com o tronco ileocecocólico.

\section{SUMMARY}

The constitution of the portal vein in Nelore bovines has been studied in 30 fetuses. The extrahepatic portion of the portal vein and its roots were injected with colored Neoprene latex and, then, dissected. Variations in the arrangement of the tributaries and branches of the portal vein were described. The most frequent disposition was the portal vein constituted of the esplenic, gastroduodenal and cranial mesenteric veins.

UNITERMS: Portal vein; Cattle; Nelore

\section{REFERÊNCIAS BIBLIOGRÁFICAS}

01-BRUNI, A.C.; ZIMMERL, U. Anatomia degli animali domestici. Milano, Francesco Vallardi, 1951.

02-DYCE, K.M.; SACK, W.O.; WENSING, C.J.C.Tratadode anatomia veterinária. Rio de Janeiro, Guanabara, $439-55,1987$.

03-GETTY, R. Anatomia dos animais domésticos. 5.ed. Rio de Janeiro, Interamericana, 1981. p.922.

04-GHOSKAL. N.G.; KOCH, T.; POPESKO.P. The venous drainage of the domestic animals. Philadelphia, W.B. Saunders, 1981. p.145-51.

05-HOROWITZ. A.; VENZKE. G. Distribution of blood vessels to the postdiaphragmatic digestive tract of the goat. Celiac trunk-gastroduodenal and splenic tributaries of the portal vein. Amer. J. vet. Res., v.27, p.1293-315. 1966.
06-KUHN, H. von ROTHKEGEL, R. Beitrag zur makroskopischen Anatomie der V. Portae der Schafer (Ovis aries). Anat. Anz., v.1 10, p.312-21, 1962.

07-LESBRE, F.X.Précis d'anatomie comparée des animaux domestiques. Paris, J.B. Baillière, 1922.

08-NICKEL, R.; SCHUMMER, A.; SEIFERLE, E. The anatomy of the domestic animals. The circulatory system, the skin and the cutaneous organs of the domestic mammals. 1981. v.3, p.260-5.

Recebido para publicação em 22/09/92 Aprovado para publicação em 07/04/93 